\title{
Evaluation of Virtual Reality Technology and Online Teaching System for Medical Students in Ukraine During COVID-19 Pandemic
}

\author{
https://doi.org/10.3991/ijet.v16i23.26099 \\ Tsekhmister Yaroslav Volodymyrovych $\left.{ }^{1}{ }^{(}\right)$, Konovalova Tetiana $^{1}$, \\ Tsekhmister Bogdan Yaroslavovych ${ }^{1}$, Amit Agrawal ${ }^{3}$, Dipanjana Ghosh ${ }^{4}$ \\ ${ }^{1}$ Bogomolets National Medical University, Kyiv, Ukraine \\ ${ }^{3}$ Gandhi Medical College \& Kamla Nehru Hospital, Bhopal, India \\ ${ }^{4}$ People's University, Bhopal, India \\ kancnmu@nmu.ua
}

\begin{abstract}
A study has been conducted to evaluate the virtual reality technology and online teaching system among medical students of Bogomolets National Medical University, Ukraine during COVID-19 pandemic. The final questionnaire contained the 15 questions with 5 options to comprehensively evaluate the virtual reality technology and online teaching system. The feedback of the survey was analyzed to find effectiveness of virtual reality technology and online teaching in medical education in Ukraine. Data of survey reflected that mostly students adopted and agreed on virtual reality technology and online teaching and admitted that these technologies are best alternatives to physical learning with the $65.79 \%$ an agreement with the user-friendly interface for virtual reality and online teaching system, while, $64.03 \%$ showed an agreement that virtual reality and online teaching system compensated the suspension of face-to-face medical education during the COVID-19. During online learning, there was ample time for educational activities as depicted from their response of $36.84 \%$ as strongly agree, $35.96 \%$ as agree, $6.14 \%$ as disagree, $4.39 \%$ as strongly disagree and $16.67 \%$ as neither agree nor disagree. Tutors/teachers also enjoyed virtual reality and online learning through their experience and flexibility in time management. Likewise, the results of all questions showed positive reviews and encouraged virtual reality and online teaching in academic continuity and stability in medical education in Ukraine. It can be concluded that digital learning environments are extremely effective in terms of medical students and staff satisfaction, accomplishment, and technical learning skill growth.
\end{abstract}

Keywords - virtual reality technology, online teaching system, medical education

\section{Introduction}

The World Health Organization (WHO) has declared coronavirus infection (COVID-19) as a pandemic since $11^{\text {th }}$ March 2020 due to its uncontrolled spread [1] 
followed by the closure of global universities/ educational institutions [2]. Many students' attendance, cognition and learning were hampered by the COVID-19 lockdown, which created psychological stress or anxiety among students and academic staff [3, 4]. Online learning in medical education may represent an alternative to traditional learning by providing the medical students updated information on a regular basis. An abrupt shift from a conventional learning system to online learning was made for smooth learning and education in continuation of the academic curriculum [5]. The resultant educational transformation was achieved in terms of technological modernization and digitalization [6]. Most of the countries were not prepared for such conditions and had a lack of technical support or training, that's why their interns/medical students faced various issues regarding online learning. However, this is the only suitable way for providing knowledge by means of teaching learning processes via various online learning platforms [6-8]. Similar to the world, all higher educational institutions of Ukraine started online learning; initially, it was not organized properly and hence decreased the quality of education. The use of a variety of online learning platforms caused frustration in students and negatively contributed to the quality of online learning. Moreover, for medical students it was difficult to acquire practical and clinical skills that are required to become a competent clinician. Consequently, solving these problems requires comprehensive online learning plans [9]. Different approaches and technologies have been developed to overcome the issues in online learning. However, the present study was designed to evaluate the virtual reality technology and online teaching system among medical students of Bogomolets National Medical University, Ukraine during COVID19 pandemic.

\section{Literature review}

\subsection{The COVID-19 pandemic and online learning}

The COVID-19 started in Wuhan province, China in late December 2019. Initially, it could not imagine the suffering of this disease which was imagining how drastically the world was about to change due to it [10], hence, every biotic and even abiotic factors of society forced to reconsider, rearrange, and restructure to nullify the effect of this pandemic. An unpredicted revolution has been imposed on us by this pandemic and in almost all fields, technology has been at the heart of our adaptations to compensate our social needs and demands. This outbreak has also resulted in a worldwide disruption of medical education, limiting practical exposure to clinical specialties, as well as the suspended student's internship in hospitals, decreasing performance and competency [11]. An immediate solution to this problem necessitated a greater awareness of online education among medical students [12]. In response to COVID-19, a private school in Georgia provided online instruction to 920 students in 47 virtual classes utilising Google Hangouts [13]. The usefulness of digital technology for lifelong online learning and continual professional development has been evaluated by several studies [14].

The development of various electronic devices has made it easier to deliver instruction outside of traditional physical classrooms. Because of the Internet and technologies 
like Google Docs, Skype, Google Hangouts, and Wikis, education has become more collaborative, participatory, and efficient [15]. Higher education is no longer restricted to the physical classroom; on the contrary, current technological advancements have made it possible to provide education to people located everywhere on the planet [16]. For online learning, Learning Management Systems (LMS) has frequently been utilised. Even before COVID-19, educational technology was rapidly expanding and becoming accepted, with global Edtech investments reaching US\$18.66 billion in 2019 and the overall market for virtual education expected to reach $\$ 350$ billion by 2025 . Since the eruption of COVID-19, there has been a significant increase in the use of online technologies [17]. It has a wide range of direct and indirect effects on nearly every worldwide industry, with education being one of the most prominent. For evaluation of the online system, daily assessments of the online learning process have been undertaken in order to measure the efficacy of the move to remote education [18]. Alasmari [19] utilized a quantitative method, with a survey questionnaire as the data collecting instrument, and found that emergency distance education had an impact on instructors and students' learning experiences in Jeddah, Saudi Arabia. The quantitative findings showed that during COVID-19, an effective and efficient infrastructure is critical for guaranteeing smooth learning. Similarly, Elzainy, et al. [20] conducted a satisfaction survey about the online learning experiences and reported $58.82 \%$ high satisfaction towards online assessment, virtual classrooms, and online workshops. Their findings backed up the move toward more online medical courses in the future. Moreover, Shahid, et al. [21] determined the viewpoints of undergraduate medical students pertinent to online education carried out by their teachers amid the COVID-19 pandemic. Their results showed that medical students were sufficiently content with the online teaching of their respective teachers and e-learning proved to be very advantageous in academic continuity and stability. Cheng, et al. [22] after the pandemic, $36.2 \%$ of respondents chose to utilise online instruction of theoretical sessions, while $24.8 \%$ instructors were eager to return to conventional face-to-face anatomy education.

Nonetheless, despite the many benefits of LMS, a number of online learning programmes aided by them, particularly in developing countries, have been completely or partially unsuccessful $[23,24]$. This technique allows higher educational institutions to shorten terms, provide additional courses, and reach learners throughout the country or the globe since it allows students to learn at any time and from any location. It also makes preliminary and advanced instruction and learning more accessible to a broader group of students. In order for online education to be successful, colleges must provide virtual registration, automatic access to materials, and fast responses to questions [2527].

For medical students, there is a need for technology that can fill the gap of physical education and clinical practices as there is a need for practical knowledge. As an alternative, virtual reality technologies have been developed to compensate for these gaps in online learning. The medical students showed a preference to virtual learning over physical learning most probably due to the fact that students easily attend classes at a convenient time and can hear the recorded lectures many times and virtually perform practical [29]. In the midst of the COVID-crisis, Goian, et al. [30] developed a successful distance educational approach, which had a direct impact on the quality of practical 
training of experts in the field of audio-visual media and arts. Maskati, et al. [31] also reported that virtual reality is a new method that has shown to be beneficial in both teaching and entertainment. It encourages students to study, engage, and improve the efficiency of the learning process. The suggested application successfully helped kids learning in general and students with dyslexia in particular, according to the system's review. As a consequence, a virtual laboratory model was created, which is particularly for those who have hearing and visual impairments, as well as musculoskeletal diseases. Similarly, the virtual teaching assistant e-learning module has also been created to assist medical students who are now pursuing a career as a professional medical practitioner in Indonesian hospitals [32-33]. According to another research, live streaming lectures effectively compensated for the loss of face-to-face instruction and gave additional opportunities for open conversation [34]. However, Goh and Sandars [35] claimed that educators' technological skills could be enhanced via live streaming apps. As previously stated, successful collaborative online learning required the assistance of IT experts [34, 36]. Similarly, Ulfa and Fatawi [29] predicted student activities in online learning and confirmed that working on activities while utilizing concept mapping improves students learning outcomes significantly.

\subsection{Medical education, virtual reality and online learning}

The use of immersive technologies help teachers and students of higher education in various specializations at the modern level. Whereas, virtual reality technology is one of the immersive technologies with a three-dimensional (3D) environment that a person can interact with. In fact, with the help of virtual reality glasses, the brain perceives what is visible as real using special technologies. The virtual reality system in medicine is gaining great popularity as it helps not only in medical education, but also directly applies in the medical process. Students enthusiastically perceive the acquired knowledge and note the positive impact of these technologies on the assimilation of material in the disciplines Biology,Medicine,Human Anatomy, Physiology, Pathophysiology, etc. Virtual reality technology allows us to see the organs and processes in 3D projection in real time, observe and work out manipulations, combine practice and large amounts of information. The virtual reality system is equipped not only with a graphical headset, but also with tatty feedback. The doctor has a mechanical effect on the organs of the "patient". With the help of such a simulator, you can get the skills necessary for successful operations at much lower costs. Further, education materials posted on higher education institutions can be used in complementing lessons and online consultations in Zoom and Skype [37]. The online learning of medical students has some advantages such as a large number of participants from the whole world with different experiences of practice. In this way, participants share knowledge for maintaining quality of life, increasing medical knowledge for betterment of health [38]. There is no need for classrooms, chairs, and other electrical appliances for the assistance of class [39]. It is also accessible to remote areas as well as reduces the operating expenses, as well as improving academic performance by increasing the number of students, as well as the creation of new educational institutions in hard-to-reach areas [40]. It is also considered very helpful for people with disabilities. This is evidenced by the performance level of 
the "disabled student", which is equal to the average value of other normal students [41]. As a consequence, when compared to face-to-face instruction, the quality of online learning is comparable [42]. Furthermore, the usage of audio/video in online learning will improve participant interactions, particularly among women [43].

\section{$3 \quad$ Methodology}

\subsection{Study design}

For the evaluation of virtual reality and online teaching system in Ukraine a selfdesigned structured questionnaire based on a five-point Likert scale was designed for medical students of Bogomolets National Medical University, Ukraine. The final questionnaire contained the 15 questions with 5 options: strongly agree, agree, disagree, strongly disagree and neither agree nor disagree to comprehensively express the virtual reality and online teaching system. The questions $1,2,3,4,5,6 \& 7$ of this survey are more elementary and critical whereas questions $8,9,10$ and 11 are related to lecture assignment self-direction, motivation and critical thinking. Questions $12 \& 13$ are related to workload management and engagement in self-education. While, question 14 $\& 15$ are about the feedbacks related to tutors/teachers wherein the opinions of participants.

Participating students are medical students in their clinical medical years (i.e., $3^{\text {rd }}$, $4^{\text {th }}$, and $5^{\text {th }}$ years). From estimated sample size of three hundred students, 226 consented to participate in this study. The questionnaire was distributed through email and WhatsApp. The participant's demographic profile (age group, gender distribution) and academic years) were also recorded. All selected participants of the survey have internet and e-learning gadget access and are familiar with using these for virtual learning purposes. The collected data from these experienced and actively practitioner interns were used to measure the perception of the users acceptance of virtual reality technology and online learning system.

\section{$4 \quad$ Results}

From a total of three hundred participants only 226 medical students in their clinical years from Bogomolets National Medical University, Ukraine consented to participate in this study. Whereas, from all consented participants, 114 filled the questionnaire and returned back. The results of the demographic profile showed that the percentage of female $(82.46 \%)$ participants was higher than the male (17.54\%) participants. Similarly, the most of the participants were from an age group of $22-25$ years $(46.49 \%)$ while lowest percentage (15.79\%) was from an age group of 26-29 years as presented in Figure 1. The medical students participated in this study were from their $3^{\text {rd }}, 4^{\text {th }}$, and $5^{\text {th }}$ clinical years. From those highest percentage was from $4^{\text {th }}$ year $(48.25 \%)$ as presented in Figure 1. 


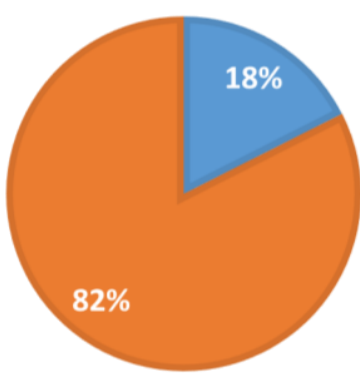

Gender Distribution

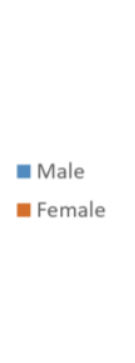

$16 \%$

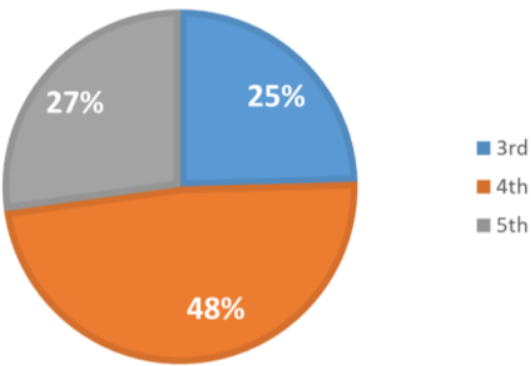

Academic Year

$16 \%$

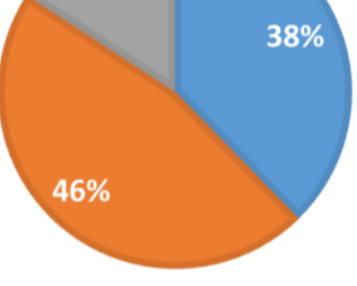

Age group

Fig. 1. Demographic profile of the study participants

The results of the data obtained from the questionnaire showed overall positive response for acceptance of virtual reality and online teaching system (Table 1). The survey results showed that $65.79 \%$ participants were agreed with the user-friendly interface for virtual reality and online teaching system. In contrast, $64.03 \%$ said that virtual reality and online teaching systems compensated for the suspension of face-to-face medical education during the COVID-19. The question 3 was related to whether the educational activities got enough time during the virtual teaching and online learning received. The responses to this question were $36.84 \%$ as strongly agree, $35.96 \%$ as agree, $6.14 \%$ as disagree, $4.39 \%$ as strongly disagree and $16.67 \%$ neither agree nor disagree. The questions 1 to 7 were more elementary and critical, the resulted feedback was absolutely positive with strongly agree and agree opinions on virtual reality technology and online learning with user friendly interface. The results also depicted that the online teaching system compensated the interruption of physical teaching as students got enough time for educational activities during the virtual teaching. Similarly, questions 8 to 11 were related to lecture assignment self-direction, motivation and critical thinking. The results showed that students strongly agreed that class assignment not only effective for knowledge but also compensate the physical education deficiency because it drives and motivates the medical students that they can think critically and raise knowledge-based questions. While, the results of questions $12 \& 13$ were also positive that students has enough time to manage workload of self-education and engage them in self-education. In question $14 \& 15$ recorded results showed that teachers/tutors were expert in virtual and online learning requirements and this system also provided flexibility of time to tutors/ teachers. 
Table 1. Questionnaire for evaluation of virtual reality technology and online teaching system for medical students during COVID-19 pandemic

\begin{tabular}{|c|c|c|c|c|c|c|c|c|c|c|c|}
\hline \multirow[t]{3}{*}{ \# } & \multirow[t]{3}{*}{ Questions } & \multicolumn{10}{|c|}{ Responses } \\
\hline & & \multicolumn{2}{|r|}{ SA } & \multicolumn{2}{|r|}{$\mathbf{A}$} & \multicolumn{2}{|c|}{ DA } & \multicolumn{2}{|c|}{ SD } & \multicolumn{2}{|c|}{ NAND } \\
\hline & & $N$ & $\%$ & $n$ & $\%$ & $n$ & $\%$ & $n$ & $\%$ & $n$ & $\%$ \\
\hline 1 & $\begin{array}{l}\text { Virtual reality technology and online teaching system } \\
\text { had a user-friendly interface }\end{array}$ & 27 & 23.68 & 48 & 42.11 & 19 & 16.67 & 10 & 8.77 & 10 & 8.77 \\
\hline 2 & $\begin{array}{l}\text { Virtual reality technology and online teaching system } \\
\text { compensated for the COVID-19 suspension of physical } \\
\text { education }\end{array}$ & 28 & 24.56 & 45 & 39.47 & 12 & 10.53 & 9 & 7.89 & 20 & 17.54 \\
\hline 3 & $\begin{array}{l}\text { Educational activities were given adequate time during } \\
\text { the virtual teaching and online learning }\end{array}$ & 42 & 36.84 & 41 & 35.96 & 7 & 6.14 & 5 & 4.39 & 19 & 16.67 \\
\hline 4 & $\begin{array}{l}\text { Enough theoretical and practical knowledge was } \\
\text { gained through virtual reality technology and online } \\
\text { teaching }\end{array}$ & 58 & 50.88 & 41 & 35.96 & 2 & 1.75 & 1 & 0.88 & 12 & 10.53 \\
\hline 5 & $\begin{array}{l}\text { Real time student-teacher and student-student interac- } \\
\text { tion levels was maintained during virtual reality tech- } \\
\text { nology and online teaching }\end{array}$ & 61 & 53.51 & 34 & 29.82 & 2 & 1.75 & 1 & 0.88 & 16 & 14.04 \\
\hline 6 & $\begin{array}{l}\text { All the learning objectives were achieved in time dur- } \\
\text { ing the online learning }\end{array}$ & 51 & 44.74 & 47 & 41.23 & 2 & 1.75 & 1 & 0.88 & 13 & 11.40 \\
\hline 7 & $\begin{array}{l}\text { Virtual reality technology and online teaching help to } \\
\text { sustain pre-vocational training in medical specialties } \\
\text { during COVID-19 pandemic }\end{array}$ & 58 & 50.88 & 49 & 42.98 & 2 & 1.75 & 2 & 1.75 & 3 & 2.63 \\
\hline 8 & $\begin{array}{l}\text { Online learning aids in the development of self-di- } \\
\text { rected learning abilities and increases learning motiva- } \\
\text { tion }\end{array}$ & 64 & 56.14 & 45 & 39.47 & 2 & 1.75 & 1 & 0.88 & 2 & 1.75 \\
\hline 9 & $\begin{array}{l}\text { The development of self-directed learning abilities aids } \\
\text { virtual teaching and online learning }\end{array}$ & 52 & 45.61 & 46 & 40.35 & 2 & 1.75 & 2 & 1.75 & 12 & 10.53 \\
\hline 10 & $\begin{array}{l}\text { Virtual reality technology and online teaching promote } \\
\text { the development of critical thinking and helps to im- } \\
\text { prove computer literacy }\end{array}$ & 37 & 32.46 & 48 & 42.11 & 4 & 3.51 & 9 & 7.89 & 16 & 14.04 \\
\hline 11 & $\begin{array}{l}\text { Online assessments are useful for determining a per- } \\
\text { son's knowledge }\end{array}$ & 52 & 45.61 & 47 & 41.23 & 5 & 4.39 & 7 & 6.14 & 3 & 2.63 \\
\hline 12 & $\begin{array}{l}\text { Workload management was equivalent during face-to- } \\
\text { face and virtual / online learning }\end{array}$ & 40 & 35.09 & 52 & 45.61 & 2 & 1.75 & 6 & 5.26 & 14 & 12.28 \\
\hline 13 & $\begin{array}{l}\text { Virtual and online learning leads to self-education/ self- } \\
\text { study as social communication affected during COVID-19 }\end{array}$ & 28 & 24.56 & 51 & 44.74 & 11 & 9.65 & 9 & 7.89 & 15 & 13.16 \\
\hline 14 & $\begin{array}{l}\text { Tutors/ teachers was expert in virtual and online learn- } \\
\text { ing requirements }\end{array}$ & 44 & 38.60 & 48 & 42.11 & 10 & 8.77 & 2 & 1.75 & 10 & 8.77 \\
\hline 15 & $\begin{array}{l}\text { Virtual reality and online teaching system provide flex- } \\
\text { ibility to teachers }\end{array}$ & 38 & 33.33 & 56 & 49.12 & 5 & 4.39 & 7 & 6.14 & 8 & 7.02 \\
\hline
\end{tabular}

$\mathrm{SA}=$ strongly agree, $\mathrm{A}=$ Agree, $\mathrm{DA}=$ Disagree, $\mathrm{SD}=$ Strongly disagree, $\mathrm{NAND}=$ Neither agree nor disagree

The responses from all 15 questions have been presented in Table 1. The survey data reflects the students' opinion that virtual learning has prodigious benefits and mostly participants replied with highest percentages of the responses as strongly agree and agree. Whereas, a very low percentage of disagreement has been observed. Some students also stated that by doing daily assessments of the online learning process, the value of virtual education was considerably increased. 


\section{Discussion}

During the COVID-19 pandemic, most medical schools shut down their clinical settings [44]. Advanced technology, like virtual-reality simulators, arose during the epidemic to maintain global medical education $[45,46]$. The significance of modern technology in medical education was recognised in the Horizon 2020 Teaching and Learning report. This pandemic might be a blessing in enabling our teachers to become skilled at distant teaching proficiencies in the best interest of their students.

In this study, we have conducted a survey from medical students of Bogomolets National Medical University, Ukraine with pre-designed questions. The percentage of female $(82.46 \%)$ participants was higher than the male $(17.54 \%)$ participants. Similarly, the most of the participants were from an age group of $22-25$ years $(46.49 \%)$. While, the highest percentage was from $4^{\text {th }}$ year $(48.25 \%)$ these findings are comparable and similar to previously reported studies [21, 51]. The questions $1,2,3,4,5,6$ \& 7 were more elementary and critical, the survey feedback was absolutely positive with strongly agree and agree opinions on virtual reality technology and online learning with user friendly interface. It was also observed during this study that the online teaching system compensated the interruption of physical teaching as students got enough time for educational activities during the virtual teaching. These results are comparable and similar to other studies $[18,29,47,48]$. The participants preferred virtual reality technology and online learning over physical learning that might be due to the fact that students can easily attend classes at a convenient time [29]. A similar study was also conducted during this pandemic also highlighted the need for zest, dynamicity, and interactivity to keep the students vigilant and attentive during e-learning sessions [47]. Moreover, another study showed that online or e-learning provides more time to interact with tutors, as well as other students during interactive sessions via mobile phones or laptops with ample internet access [48, 49]. However, the standard of online courses can sufficiently be improved by keen interest and quality time investment in content delivery by our tutors. However, virtual learning has little bit deficiency of hands-on training as compared to physical training of medical students as reported in this study. It is because of hands-on training has no alternate way, physical appearance of medical students/inters are important at medical centre for pre-vocational training in medical specialties.

Similarly, questions $8,9,10$ and 11 in present study were related to lecture assignment self-direction, motivation and critical thinking. The feedback shows that students strongly agreed that class assignment not only effective for knowledge but also compensate the physical education deficiency because it drives and motivates the medical students that they can think critically and raise knowledge-based questions. All these feedbacks also supported already reported data of medically and non-medically students $[18,29,47,48,50]$. While, in questions $12 \& 13$ on our study, feedbacks were also positive that students have enough time to manage workload of self-education and engage them in self-education and it is already discussed that medical students has sufficient time for educational activities during the virtual teaching and online learning $[18,35,48,50]$. 
In question $14 \& 15$ of the present survey, the feedbacks related to tutors/teachers were recorded wherein the opinions of participants, they were expert in virtual and online learning requirements and this system also provided flexibility of time to tutors/ teachers. These findings were also supported by already reported surveys $[18,29,47$, $48,50-52]$. Similar study based on a questionnaire was conducted by Al-Balas, et al. [51] in medical colleges in this pandemic and shows that are agreement with our feedback and moreover, that study reported the improvement in satisfaction rate of students than the previous online learning in their medical institutes because during pandemic educational and study material was provided timely. Similarly, Firmansyah, et al. [52] showed that students thought online learning was more flexible, efficient, and effective in terms of time, cost, and energy, thus it was embraced by them.

\section{Conclusions}

The current work explored the virtual reality technology and online teaching system for medical students in Bogomolets National Medical University, Ukraine during COVID-19 pandemic were promising strategies with great educational potentials. An overall satisfactory response towards the digital learning environment was observed through a self-designed questionnaire. This study reported that the online teaching system compensated the interruption of physical teaching as medical students got enough time for educational activities and practical skills using virtual reality technology. It can be concluded that virtual reality technology and online teaching is vital for academic continuity and stability of medical education and general secondary education in Ukraine.

\section{$7 \quad$ References}

[1] R. Raut et al., "Impact of COVID-19 on neurosurgery in LMIC: training and service delivery in a tertiary care hospital in Pakistan," Indian Journal of Neurotrauma, vol. 18, no. 01, pp. 93-94, 2021. https://doi.org/10.1055/s-0040-1716422

[2] A. Smalley, "Higher education responses to coronavirus (COVID-19)," in National Conference of State Legislatures, 2020, vol. 6, p. 15.

[3] P. Sahu, "Closure of universities due to coronavirus disease 2019 (COVID-19): impact on education and mental health of students and academic staff," Cureus, vol. 12, no. 4, 2020. https://doi.org/10.7759/cureus. 7541

[4] W. Cao et al., "The psychological impact of the COVID-19 epidemic on college students in China," Psychiatry research, vol. 287, p. 112934, 2020.

[5] V. D. Soni, "Global Impact of E-learning during COVID 19," Available at SSRN 3630073, 2020.

[6] A. E. McFarlane, "Devices and desires: Competing visions of a good education in the digital age," British Journal of Educational Technology, vol. 50, no. 3, pp. 1125-1136, 2019. https://doi.org/10.1111/bjet.12764

[7] I. Prokopenko and S. Berezhna, "Higher education institutions in Ukraine during the coronavirus, or COVID-19, outbreak: new challenges vs new opportunities," 2020. https://doi.org/10.18662/rrem/12.1sup2/256 
[8] C. C. La Torre Castillo, "Virtual Classroom Usage and User Perception for English Learning as a Second Language at Universities in Lima, Peru," International Journal of Emerging Technologies in Learning, vol. 16, no. 8, 2021. https://doi.org/10.3991/ijet.v16i08.19221

[9] I. S. Mintii, T. A. Vakaliuk, S. M. Ivanova, O. A. Chernysh, S. M. Hryshchenko, and S. O. Semerikov, "Current state and prospects of distance learning development in Ukraine," in CEUR Workshop Proceedings, 2021.

[10] Z. Chauhdary and U. Saleem, "COVID-19 China epidemic, characteristics of SARS-CoV2, its transmission and prevention," J Toxicol Pharmaceut Sci, vol. 5, no. 1, pp. 24-29, 2021.

[11] H. Ahmed, M. Allaf, and H. Elghazaly, "COVID-19 and medical education," The Lancet Infectious Diseases, vol. 20, no. 7, pp. 777-778, 2020. https://doi.org/10.1016/s14733099(20)30226-7

[12] Y. Iwai, "Online learning during the COVID-19 pandemic what do we gain and what do we lose when classrooms go virtual," Scientific American, vol. 13, 2020.

[13] G. Basilaia and D. Kvavadze, "Transition to online education in schools during a SARSCoV-2 coronavirus (COVID-19) pandemic in Georgia," Pedagogical Research, vol. 5, no. 4, 2020. https://doi.org/10.29333/pr/7937

[14] D. A. Cook, A. J. Levinson, S. Garside, D. M. Dupras, P. J. Erwin, and V. M. Montori, "Internet-based learning in the health professions: a meta-analysis," Jama, vol. 300, no. 10, pp. 1181-1196, 2008. https://doi.org/10.1001/jama.300.10.1181

[15] M. F. H. Sarker, R. Al Mahmud, M. S. Islam, and M. K. Islam, "Use of e-learning at higher educational institutions in Bangladesh: Opportunities and challenges," Journal of Applied Research in Higher Education, 2019. https://doi.org/10.1108/jarhe-06-2018-0099

[16] J. F. Strayer, "How learning in an inverted classroom influences cooperation, innovation and task orientation," Learning environments research, vol. 15, no. 2, pp. 171-193, 2012. https://doi.org/10.1007/s10984-012-9108-4

[17] L. Cathy and L. Farah, "Entertainment and Information Industries," in World Economic Forum. Available at:(accessed 05 09, 2020), 2020.

[18] S. Voloshinov, V. Kruglyk, V. Osadchyi, K. Osadcha, and S. Symonenko, "Realities and prospects of distance learning at higher education institutions of Ukraine," 2020. https://doi.org/10.32919/uesit.2020.01.01

[19] T. Alasmari, "Learning in the COVID-19 Era: Higher Education Students and Faculty's Experience with Emergency Distance Education," International Journal of Emerging Technologies in Learning, vol. 16, no. 9, 2021. https://doi.org/10.3991/ijet.v16i09.20711

[20] A. Elzainy, A. El Sadik, and W. Al Abdulmonem, "Experience of e-learning and online assessment during the COVID-19 pandemic at the College of Medicine, Qassim University," Journal of Taibah University Medical Sciences, vol. 15, no. 6, pp. 456-462, 2020. https://doi.org/10.1016/j.jtumed.2020.09.005

[21] R. Shahid, S. Zeb, S. Yasmeen, M. Umar, R. Asghar, and M. Batul, "Evaluation of Online teaching by Undergraduate medical students of Rawalpindi Medical University amidst COVID-19 pandemic," Journal of Rawalpindi Medical College, vol. 25, no. 2, pp. 175-180, 2021. https://doi.org/10.37939/jrmc.v24i4.1457

[22] X. Cheng, L. K. Chan, S.-Q. Pan, H. Cai, Y.-Q. Li, and X. Yang, "Gross anatomy education in China during the Covid-19 pandemic: A national survey," Anatomical Sciences Education, vol. 14, no. 1, pp. 8-18, 2021. https://doi.org/10.1002/ase.2036

[23] P. Zaharias and C. Pappas, "Quality management of learning management systems: A user experience perspective," Current Issues in Emerging eLearning, vol. 3, no. 1, p. 5, 2016.

[24] H. Al-Samarraie, B. K. Teng, A. I. Alzahrani, and N. Alalwan, "E-learning continuance satisfaction in higher education: a unified perspective from instructors and students," Studies 
in higher education, vol. 43, no. 11, pp. 2003-2019, 2018. https://doi.org/10.1080/03075079 .2017 .1298088

[25] S. Kaini and L. Z. Motie, "Virtual vs online: Insight from medical students. Comment on 'effectiveness of virtual medical teaching during the COVID-19 crisis: Systematic review,"” JMIR Med. Educ., vol. 7, no. 2, p. e27020, 2021. https://doi.org/10.2196/27020

[26] N. Volles, "Lifelong learning in the EU: changing conceptualisations, actors, and policies," Studies in higher education, vol. 41, no. 2, pp. 343-363, 2016. https://doi.org/10. $1080 / 03075079.2014 .927852$

[27] J. Yoon, E. Yang, J. Lee, and S. J. Hwang, "Lifelong learning with dynamically expandable networks," arXiv preprint arXiv: 1708.01547, 2017.

[28] J. Martinez, E. Phillips, and O. Fein, "Perspectives on the changing healthcare system: teaching systems-based practice to medical residents," Med. Educ. Online, vol. 18, no. 1, p. 20746, 2013. https://doi.org/10.3402/meo.v18i0.20746

[29] S. Ulfa and I. Fatawi, "Predicting Factors That Influence Students' Learning Outcomes Using Learning Analytics in Online Learning Environment," International Journal of Emerging Technologies in Learning (iJET), vol. 16, no. 1, pp. 4-17, 2021. https://doi.org/10. 3991/ijet.v16i01.16325

[30] V. Goian, O. Goian, and T. Biletska, "Management Priorities of Audiovisual Student Projects During the COVID-Crisis," International Journal of Emerging Technologies in Learning, vol. 16, no. 10, 2021. https://doi.org/10.3991/ijet.v16i10.19679

[31] E. Maskati, F. Alkeraiem, N. Khalil, R. Baik, R. Aljuhani, and A. Alsobhi, "Using Virtual Reality (VR) in Teaching Students With Dyslexia," International Journal of Emerging Technologies in Learning, vol. 16, no. 9, 2021. https://doi.org/10.3991/ijet.v16i09.19653

[32] R.-J. Wilcha, “Author's reply to: Virtual vs online: Insight from medical students. Comment on 'effectiveness of virtual medical teaching during the COVID-19 crisis: Systematic review,"” JMIR Med. Educ., vol. 7, no. 2, p. e29335, 2021. https://doi.org/10.2196/29335

D. Purbohadi, S. Afriani, N. Rachmanio, and A. Dewi, "Developing Medical Virtual Teaching Assistant Based on Speech Recognition Technology," International Journal of Online \& Biomedical Engineering, vol. 17, no. 4, 2021. https://doi.org/10.3991/ijoe.v17 $\underline{\mathrm{i} 04.21343}$

[34] L. McCoy et al., "Developing technology-enhanced active learning for medical education: challenges, solutions, and future directions," Journal of Osteopathic Medicine, vol. 115, no. 4, pp. 202-211, 2015.

[35] P.-S. Goh and J. Sandars, "A vision of the use of technology in medical education after the COVID-19 pandemic," MedEdPublish, vol. 9, 2020. https://doi.org/10.15694/mep.2020. 000049.1

[36] D. Kolbaek, "Problem-Based Learning in the Digital Age," International Association for Development of the Information Society, 2018.

[37] F. Hajjej, S. Ayouni, H. Shaiba, and A. S. Alluhaidan, "Student Perspective-Based Evaluation of Online Transition During the COVID-19 Outbreak: A Case Study of PNU Students," International Journal of Web-Based Learning and Teaching Technologies (IJWLTT), vol. 16, no. 5, pp. 21-38, 2021. https://doi.org/10.4018/ijwltt.20210901.oa2

[38] I. Chorbev, M. Sotirovska, and D. Mihajlov, "Virtual communities for diabetes chronic disease healthcare," International journal of telemedicine and applications, vol. 2011, 2011. https://doi.org/10.1155/2011/721654

[39] C. Sorensen, "Classrooms without walls: A comparison of instructor performance in online courses differing in class size," MERLOT Journal of Online Learning and Teaching, vol. 10, no. 4, pp. 569-576, 2014. 
[40] M. Gordon, J. Hodson, and J. Kitchen, "Lessons Learned: Effectiveness of Courses Developed for Aboriginal Teacher Candidates Delivered at a Distance," International Journal of E-Learning \& Distance Education, vol. 29, no. 2, p. n2, 2014.

[41] M. Shonfeld and I. Ronen, "Online learning for students from diverse backgrounds: learning disability students, excellent students and average students," IAFOR Journal of Education, vol. 3, no. 2, pp. 13-29, 2015. https://doi.org/10.22492/ije.3.2.01

[42] A. V. Fonolahi, M. G. Khan, and A. D. Jokhan, "Are students studying in the online mode faring as well as students studying in the face-to-face mode? Has equivalence in learning been achieved?," Journal of Online Learning and Teaching, vol. 10, no. 4, pp. 598-609, 2014.

[43] Y.-H. Ching and Y.-C. Hsu, "Online graduate students' preferences of discussion modality: Does gender matter?," Journal of Online Learning and Teaching, 2015.

[44] B. Murphy, "COVID-19: how the virus is impacting medical schools," Am Med Assoc, 2020.

[45] J. Bateman, M. E. Allen, J. Kidd, N. Parsons, and D. Davies, "Virtual patients design and its effect on clinical reasoning and student experience: a protocol for a randomised factorial multi-centre study," BMC medical education, vol. 12, no. 1, pp. 1-8, 2012. https://doi.org/ $\underline{10.1186 / 1472-6920-12-62}$

[46] P. S. Goh, "eLearning or technology enhanced learning in medical education-Hope, not hype," Medical teacher, vol. 38, no. 9, pp. 957-958, 2016. https://doi.org/10.3109/0142159x. 2016.1147538

[47] S. Dhawan, "Online learning: A panacea in the time of COVID-19 crisis," Journal of Educational Technology Systems, vol. 49, no. 1, pp. 5-22, 2020. https://doi.org/10.1177/ $\underline{0047239520934018}$

[48] A. A. Eldokhny and A. M. Drwish, "Effectiveness of Augmented Reality in Online Distance Learning at the Time of the COVID-19 Pandemic," International Journal of Emerging Technologies in Learning, vol. 16, no. 9, 2021. https://doi.org/10.3991/ijet.v16i09.17895

[49] V. Singh and A. Thurman, "How many ways can we define online learning? A systematic literature review of definitions of online learning (1988-2018)," American Journal of Distance Education, vol. 33, no. 4, pp. 289-306, 2019. https://doi.org/10.1080/08923647 .2019 .1663082

[50] T. H. Fatani, "Student satisfaction with videoconferencing teaching quality during the COVID-19 pandemic," BMC Medical Education, vol. 20, no. 1, pp. 1-8, 2020. https://doi.org/10.1186/s12909-020-02310-2

[51] M. Al-Balas et al., "Distance learning in clinical medical education amid COVID-19 pandemic in Jordan: current situation, challenges, and perspectives," BMC medical education, vol. 20, no. 1, pp. 1-7, 2020. https://doi.org/10.1186/s12909-020-02428-3

[52] R. Firmansyah et al., "Educational Transformation: An Evaluation of Online Learning Due to COVID-19," International Journal of Emerging Technologies in Learning, vol. 16, no. 7, 2021.

\section{Authors}

Yaroslav V. Tsekhmister, Doctor of Science, Professor, Ed. D, PhD Degree Applicant, Ukrainian Medical Lyceum at O.O. Bogomolets National Medical University, Kyiv, Ukraine. Ukrainian scientist in the sphere of medical and biological physics, professional education, theory and teaching methodology, pre-occupational training for medical specialties, Candidate of Physics and Mathematics (1995), Doctor of Pedagogy 
(2002), Laureate of Bonus for Young Scientists in the sphere of physics by National Academy of Sciences of Ukraine (2001), professor (2003), Honorary Educator of Ukraine (2007), Master of Pharmacy (2013), Master of Public Law (2017), Professor of Education and Health Management (Honoris Causa), Open University of Liberal Sciences, USA (2017), Eastern European University Network, Lublin (2018), full member of the National Academy of Pedagogical Sciences of Ukraine (Department of General Pedagogy and Philosophy of Education, 2019). Pupil of Doctor of Physics and Mathematics, Professor, Honorary Scientist and Technician of Ukraine, corresponding member in National Academy of Pedagogy of Ukraine, head at Department of Medical and Biological Physics at O.O. Bogomolets National Medical University Oleksandr Vasyliovych Chalyi. Since 1, September, 2014 due to contest he was elected to the post of the first pro-rector in scientific pedagogical activity. According to the order from MHC of Ukraine, dd. 23.04.2018 No 18-O he was appointed to the post of acting rector (until 14, September, 2018). ORCID ID: 0000-0002-7959-3691. Scopus Author: https://www.scopus.com/authid/detail.uri?authorId=35747165900

Tetiana S. Konovalova, MD, PhD, Professor (Associate) O.O. Bogomolets National Medical University, Kyiv, Ukraine, ORCID ID 0000-0002-0319-9532 (email: f.medical2@nmu.ua).

Bogdan Y. Tsekhmister, Chairman of the Scientific Society Scientific Society A.P. Romodanov of Ukrainian Medical Lyceum at O.O. Bogomolets National Medical University, Kyiv, Ukraine, ORCID ID 0000-0002-7959-3691 (email: f.medical1@nmu .ua).

Amit Agrawal, Dr. MD, Associate Professor, Department of Pediatrics, Gandhi Medical College \& Kamla Nehru Hospital, Bhopal, MP, India ORCID ID: 0000-00016316-6700 (email: agrawaldramit@yahoo.co.in).

Dipanjana Ghosh, Associate Professor School of Pharmacy and Research, People; University, Ayodhya Bypass Road, Bhanpur, Bhopal, Madhya Pradesh, Bhopal462037, India, ORCID ID: 0000-0003-0887-6798 (email: tpo@peoplesuniversity. edu.in).

Article submitted 2021-08-07. Resubmitted 2021-10-28. Final acceptance 2021-10-29. Final version published as submitted by the authors. 